\title{
Conexão por similaridade e conexão por contiguidade: a organização dos motivos argumentativos do texto ${ }^{1}$
}

\author{
Connection by similarity and connection by contiguity: the organization of the \\ argumentative motives of the text
}

\section{Bárbara Luzia Covatti Malcorra}

Pontifícia Universidade Católica do Rio Grande do Sul - PUCRS - Porto Alegre - Rio Grande do Sul - Brasil

\begin{abstract}
Resumo: Este artigo toma como ponto de partida o estudo realizado por Graeff (2012), no qual a autora percebe a ocorrência de dois processos que conectam enunciados em textos: o processo de similaridade e o processo de contiguidade. A partir disso, e com base no suporte teórico da Teoria dos Blocos Semânticos (TBS), este estudo busca verificar como os motivos argumentativos - julgamentos argumentativos completos que exprimem um aspecto argumentativo e evocam encadeamentos (CAREL, 2012) - se organizam no texto, bem como de que modo as conexões - por contiguidade e por similaridade - estabelecidas entre os enunciados permitem explicitar o sentido global. $O$ corpus da pesquisa consiste em uma crônica publicada no jornal Zero Hora. A metodologia de análise inclui (a) a divisão dos textos em trechos que exprimem motivos argumentativos; (b) a evocação de encadeamentos argumentativos tanto normativos, expressos em DC (portanto), como transgressivos, expressos em PT (no entanto); (c) a associação a cada um dos encadeamentos evocados do aspecto argumentativo do bloco semântico que expressam; (d) a identificação do tipo de conexão estabelecida entre os enunciados (por contiguidade ou por similaridade); e, por fim, (e) a explicitação do sentido global do texto. Verifica-se, nas análises, não só ocorrências de conexões por contiguidade e por similaridade entre enunciados de um mesmo trecho, mas também entre trechos diferentes. Destaca-se, assim, a possibilidade de explicitar, a partir da perspectiva da Semântica Argumentativa, a progressão temática do texto com vista ao sentido global.
\end{abstract}

Palavras-chave: Motivo argumentativo. Conexão por similaridade. Conexão por contiguidade.

\begin{abstract}
This article takes as its starting point the study by Graeff (2012), in which the author perceives the occurrence of two processes that connect utterances in texts: the process of similarity and the process of contiguity. From this e based on the theoretical support of the Theory of Semantic Blocks (TBS), this study seeks to verify how the argumentative motives - complete argumentative judgments that express an argumentative aspect and evoke chains (CAREL, 2012) - are organized in the text, as well as how the connections - by contiguity and by similarity - established between the statements make it possible to make explicit the overall meaning. The corpus is composed of one chronicle published in the newspaper Zero Hora. The methodology of analysis includes (a) the division of the texts into parts that express argumentative motives; (b) the evocation of argumentative chains both normative, expressed in DC (therefore), and transgressive, expressed in PT (however); (c) the association to each of the chains evoked of the argumentative aspect of the semantic block they express; (d) the identification of the connection established between the utterances (by contiguity or by similarity); and, finally, (e) the global meaning explanation of the discourse. It is verified not only occurrences of connections by contiguity and by similarity between utterances of the same part of the text, but also among different parts. Results suggest the possibility of explaining the thematic progression of the text from the perspective of Argumentative Semantics.
\end{abstract}

Keywords: Argumentative motive. Connection by similarity. Connection by contiguity.

\footnotetext{
${ }^{1}$ Cumpre ressaltar que este artigo foi elaborado a partir da Dissertação de Mestrado intitulada $A$ organização semântico-argumentativa do discurso: um estudo sobre as conexões entre enunciados, de autoria de Bárbara Luzia Covatti Malcorra, sob orientação da Profa. Dra. Leci Borges Barbisan, da Pontifícia Universidade Católica do Rio Grande do Sul, e com o apoio da CAPES/PROEX.
} 


\section{Considerações Iniciais}

Pretende-se, com este estudo, dar continuidade às pesquisas desenvolvidas em Semântica Argumentativa, no que se refere, mais especificadamente, à organização dos sentidos do discurso (entendido, aqui, como sinônimo de texto). Para tanto, toma-se, como ponto de partida, o artigo de Graeff (2012) intitulado $A$ conexão entre enunciados no texto com base na semântica argumentativa, no qual a autora, ao buscar explicar, dentre outras questões, como os motivos argumentativos - julgamentos argumentativos completos que exprimem um aspecto e evocam encadeamentos (CAREL, 2012) - se organizam entre si em um discurso, mostra que há dois processos que conectam enunciados em textos: o processo de similaridade e o processo de contiguidade. Como a referida autora destaca em seu artigo, é necessário ampliar o referido estudo para um número maior de textos de diferentes gêneros, a fim de verificar o funcionamento dos processos descritos e a possibilidade de generalizá-los para qualquer texto.

É nessa perspectiva, pois, que esta pesquisa se insere. Tendo adotado como suporte teórico a Teoria da Argumentação na Língua (ANL), mais especificadamente, uma de suas versões mais recentes, a Teoria dos Blocos Semânticos (TBS), este estudo busca verificar como os motivos argumentativos se organizam no texto, bem como de que modo as conexões - por contiguidade e por similaridade - estabelecidas entre os enunciados permitem explicitar o sentido global do discurso.

Com o intuito de alcançar os objetivos propostos, explicitam-se, em um primeiro momento, os principais conceitos da TBS, tais como encadeamento argumentativo, aspecto argumentativo, bloco semântico, motivo argumentativo, argumentação interna e argumentação externa. Além disso, explicitam-se os conceitos de conexão por contiguidade e conexão por similaridade, esmiuçados por Graeff (2012). Apresentam-se, na sequência, a metodologia e a análise do corpus, seguidas da discussão dos resultados. Por fim, nas considerações finais, retomam-se as questões de pesquisa, acompanhadas das respostas alcançadas neste estudo, bem como suas limitações.

\section{A Teoria dos Blocos Semânticos: o conteúdo argumentativo em foco}

Criada em 1992 com a tese de doutorado de Marion Carel, a Teoria dos Blocos Semânticos é, segundo Ducrot (2006), um prolongamento da Teoria da Argumentação na Língua, na medida em que aprofunda e radicaliza a teoria criada por JeanClaude Anscombre e ele. Entre os conceitos propostos pela teoria para descrever e explicar o sentido dos enunciados, opta-se por partir da noção de motivo argumentativo, apresentada por Carel (2012), em Argumentation et polyphonie. De acordo com a linguista,

[...] uma parte de texto constitui um 'motivo argumentativo' se, ao mesmo tempo, ela exprime um aspecto e evoca um encadeamento, isto é, se ela comunica um julgamento completo. ${ }^{2}$ (CAREL, 2012, p. 54, tradução nossa).

A parte do motivo argumentativo que diz respeito ao encadeamento argumentativo refere-se aos discursos que determinada entidade linguística evoca. (CAREL; DUCROT, 2005). Esses discursos ou melhor, esses encadeamentos argumentativos são constituídos por dois segmentos, unidos por um conector, que pode ser de dois tipos: normativo, construído por conectores do tipo portanto (donc, em francês), e transgressivo, construído por conectores do tipo no entanto (pourtant, em francês). Os referidos linguistas salientam, pois, que é nesses dois tipos de relações - normativas e transgressivas - que cada um dos segmentos encadeados ganha sentido. A partir, pois, dessa interdependência semântica estabelecida entre dois segmentos de um

\footnotetext{
2 [...] un morceau de texte constitue un 'motif argumentatif' si, à la fois, il exprime un aspect et évoque un enchaînement, c'est-àdire s'il communique un jugement complet. (CAREL, 2012, p. $54)$.
} 
encadeamento, origina-se o bloco semântico, definido pelos autores como uma entidade semântica, unitária e indecomponível. (CAREL; DUCROT, 2005).

Já a parte do motivo argumentativo que diz respeito ao aspecto argumentativo refere-se ao conjunto de encadeamentos argumentativos que expressam o sentido mais geral de um determinado enunciado. Assim, considerando-se um exemplo de encadeamento argumentativo tal como (1) Marta é boa aluna, portanto será bem-sucedida, em que o segmento A é constituído por Marta é boa aluna e o segmento B é constituído por será bem-sucedida, um possível aspecto argumentativo poderia ser expresso por ESTUDAR DC TER SUCESSO. Com isso, os linguistas destacam, pois, que um mesmo aspecto pode conter encadeamentos diversos. (CAREL; DUCROT, 2005).

Quantos aos conceitos de argumentação interna (AI) e argumentação externa (AE), Carel e Ducrot (2005) explicam que a Al de uma determinada entidade linguística é "[...] constituída por um certo número de aspectos aos quais pertencem os encadeamentos que parafraseiam esta entidade". ${ }^{3}$ (CAREL; DUCROT, 2005, p. 64, tradução nossa). Já a $A E$ de uma entidade linguística é constituída por encadeamentos argumentativos que chegam à entidade ( $\mathrm{AE}$ à esquerda) ou que partem dela ( $\mathrm{AE}$ à direita).

Com o propósito de sintetizar os conceitos vistos até aqui, toma-se emprestado o enunciado Seu pecadinho foi julgado um caso de forca, apresentado por Carel (2012). De acordo com a referida autora, é possível evocar desse enunciado o encadeamento argumentativo [roubou pequena quantidade, no entanto sofreu grande punição], que, associado ao aspecto argumentativo PEQUENO DELITO PT GRANDE PUNIÇÃO, constitui a argumentação interna (Al) de injustiça. Tem-se, aqui, nas palavras de Graeff (2012, p. 199), "um julgamento argumentativo completo ou um motivo argumentativo".

\footnotetext{
${ }^{3}$ [...] constituída por um certo número de aspectos a los que pertenecen los encadenamientos que parafrasean esta entidad. (CAREL; DUCROT, 2005, p. 64).
}

Tendo em vista tais conceitos, a TBS define-se como uma teoria do conteúdo argumentativo, uma vez que busca descrever e explicar o sentido dos enunciados. Feitas essas considerações, parte-se, na sequência, para a explicitação das noções de conexão por similaridade e conexão por contiguidade, conforme descritas por Graeff (2012).

\section{Conexão por similaridade e conexão por contiguidade}

A partir do conceito de motivo argumentativo, Carel (2012) destaca a possibilidade de se identificar dois modos de organização entre enunciados: o caso que resulta em dois motivos argumentativos e o caso que resulta em um único motivo argumentativo. O primeiro pode ser explicitado, de acordo com Graeff (2012), com o enunciado (2) Ele tinha todo tempo medo. Uma vez que alguém gritasse, ele se sobressaltava, em que é possível o emprego da expressão por exemplo entre os dois segmentos. Já o segundo pode ser exemplificado com o enunciado (3) Ele tinha medo. Sentia seu sangue gelar, em que o uso da expressão por exemplo é vetado, no entanto pode-se empregar um conector como DC ou PT entre os dois segmentos. (GRAEFF, 2012). Com base nesses dois casos, Graeff (2012), em A conexão entre enunciados no texto com base na semântica argumentativa, retoma as noções de conexão por similaridade e conexão por contiguidade, propostas por Jakobson (2003), reinterpretando-as pelo viés semântico-argumentativo e associando-as a cada um dos casos em questão.

Para a referida linguista, a conexão por similaridade diz respeito à relação que se estabelece entre "enunciados que constituem julgamentos argumentativos cujo aspecto expresso é o mesmo, sendo diferentes os encadeamentos argumentativos evocados". (GRAEFF, 2012, p. 202). A título de exemplificação, retoma-se 0 enunciado (2), explicitado pela própria autora:

(2) Ele tinha todo tempo medo. Uma vez que alguém gritasse, ele se sobressaltava. 
Note-se que, nesse tipo de conexão, é possível o emprego da expressão por exemplo entre os dois segmentos, como em (4):

(4) Ele tinha todo tempo medo. Por exemplo, uma vez que alguém gritasse, ele se sobressaltava.

Como destaca Graeff (2012, p. 201, grifo da autora), "os dois julgamentos argumentativos expressam um mesmo aspecto, que é a Al de medo (SENTIMENTO DESAGRADÁVEL DC PENSAMENTO PENOSO)". O encadeamento uma vez que alguém gritasse, ele se sobressaltava estabelece uma relação de similaridade com 0 enunciado Ele tinha todo tempo medo. Esse tipo de conexão permite, pois, que a $\mathrm{Al}$ de uma entidade linguística seja explicitada por diversas maneiras. (GRAEFF, 2012).

A conexão por contiguidade, por sua vez, se dá quando há uma "relação entre enunciados que constituem um único julgamento argumentativo, produzido pela relação entre Al e AE de uma entidade linguística". É o caso do enunciado (3):

(3) Ele tinha medo. Sentia seu sangue gelar.

Note-se que o uso da expressão por exemplo é vetado entre os enunciados. Entretanto, de acordo com Graeff (2012), pode-se colocar entre eles um conector do tipo DC ou do tipo PT, como em (5) e (6), respectivamente:

(5) Ele tinha medo, portanto sentia seu sangue gelar.

(6) Ele sentia medo, no entanto não sentia seu sangue gelar.

Graeff (2012, p. 200) esclarece que a continuação possível de Ele tinha medo vem da Al de medo (pensamento desagradável DC sentimento desagradável). Já as continuações (DC sentia seu sangue gelar e PT não sentia seu sangue gelar) são AE de medo. Assim, a continuação do discurso se faz por contiguidade do sentido da Al de medo com a AE de ter medo (ter medo DC sentir o sangue gelar ou ainda, ter medo PT não sentir o sangue gelar).

Com base nisso, a referida linguista destaca que esse segundo processo - o de contiguidade permite explicar a progressão temática do texto, isto é,

[...] permite entender como o texto mantém a coerência no desenvolvimento de seu tema. Trata-se, nesse caso, da coerência linguísticodiscursiva do texto, verificável pela análise do processo de nominalização, mais especificamente do encapsulamento anafórico de um encadeamento argumentativo inteiro. (GRAEFF, 2012, p. 207, grifo nosso).

Note-se que Graeff (2012), ao pesquisar sobre as conexões entre enunciados, não só destaca 0 importante papel de ambas para a constituição do sentido, mas também salienta a particularidade de a conexão por contiguidade poder explicar a coerência do texto, a qual a autora classifica como linguísticodiscursiva. Trata-se, pois, de uma nova definição de coerência, dada a partir dos pressupostos da Semântica Argumentativa. A linguista, com isso, abre a possibilidade de explicar tal fenômeno, por meio, especificadamente, do material linguístico dos enunciados, em suas diferentes situações de enunciação.

Com base nos conceitos norteadores apresentados até aqui, parte-se, na sequência, para a análise semântico-argumentativa de uma crônica, em que serão aplicados tais conceitos, com o intuito de alcançar os objetivos deste estudo.

\section{Metodologia e análise de um discurso}

O material de análise é constituído por uma crônica publicada no jornal Zero Hora, de Porto Alegre/RS, em março de 2017. O discurso, cumpre salientar, foi transcrito fielmente, mantendo-se a forma e o conteúdo originais. O procedimento metodológico utilizado para a análise conta com: (a) a divisão dos textos em trechos que exprimem motivos argumentativos; (b) a evocação de encadeamentos argumentativos tanto normativos, expressos em DC (portanto), como transgressivos, expressos em PT (no entanto); (c) a associação a cada um dos encadeamentos evocados do aspecto argumentativo 
do bloco semântico que expressam; (d) a identificação do tipo de conexão estabelecida entre os enunciados (por contiguidade ou por similaridade); e, por fim, (e) a explicitação do sentido global do discurso.

Passa-se, na sequência, para a leitura da crônica "A baixa cotação dos off-lines", de autoria de Martha Medeiros, seguida da análise de cada trecho do discurso.

\section{A baixa cotação dos off-lines \\ Pergunta ainda não respondida: idosos (e nem tão idosos) são obrigados a se informatizar? \\ Por: Martha Medeiros \\ 29/03/2017 - 04h00min | Atualizada em 29/03/2017 - 04h00min}

Ela estava sentada à minha frente, gloriosa aos 79 anos, uma mulher ainda bela, com a inteligência intacta, amante dos livros e do cinema, com o bom humor em pleno funcionamento, mas com uma deficiência comum a outros que nasceram na Idade da Pedra Lascada: entende bulhufas de computadores. Não usa smartphone, nem tablet, nem iPad. Está alheia ao universo virtual, que, segundo ela, não lhe faz a menor falta. Perguntou a mim: "Tenho esse direito?".

Ela mesma respondeu: "Descobri que não, não tenho".

Vive sozinha há uns 25 anos e os filhos moram em suas próprias casas: a família é unida, mas eles não são onipresentes. Nem ela deseja que estejam na sua cola, é independente o suficiente para fazer suas compras, praticar exercícios, encontrar suas amigas, ir ao banco.

Ah, ir ao banco.

Ela é correntista de um grande banco que foi absorvido por outro grande banco, coisa que todo cliente é obrigado a aceitar sem direito a dar pitaco. Ok, nenhum problema. Só que é uma mulher que gosta de ter tudo na ponta do lápis, até porque este "tudo" não é tanto assim. Ela faz contas, como qualquer cidadã. Através do extrato do seu cartão de crédito, confere seus gastos mensais. Até que soube que seu banco, agora sob nova direção, não emitiria mais extratos de papel, apenas extratos online. Ela pensou: isso é bom, economia de celulose, mas eles certamente abrirão exceção para quem está fora das redes.

E muito calmamente foi até sua agência solicitar a continuidade do recebimento do extrato pelo correio.

Foi tratada como se fosse um alienígena, um ser primitivo a ser estudado por arqueólogos. Saiu de lá sem a solução para essa questão que lhe parecia tão simples, e é.

Pergunta ainda não respondida: idosos (e nem tão idosos) são obrigados a se informatizar? Humilhá-los é uma forma de punição pelo atrevimento de não terem um iToken?

Se você não viu o filme Eu, Daniel Blake, vencedor do Festival de Cinema de Cannes do ano passado, procure assistir por algum canal pago ou pelo DVD: trata da alienação forçada e injusta imposta àqueles que pegaram a revolução tecnológica no meio do caminho e não são mais considerados pessoas que valham o esforço de um atendimento analógico.

A bela septuagenária aqui citada não é um personagem de cinema. É apenas mais uma entre tantos senhores e senhoras que se sentem excluídos por seus digníssimos gerentes de conta, que parecem esquecer que existe vida além dos aplicativos. Até onde sei, o dinheiro de alguém de 35 anos vale o mesmo que o dinheiro de quem tem o dobro dessa idade. Ou não? Bancos, lojas, repartições: não matem seus antigos clientes antes do tempo.

Fonte: Zero Hora
Trecho 1: Ela estava sentada à minha frente, gloriosa aos 79 anos, uma mulher ainda bela, com a inteligência intacta, amante dos livros e do cinema, com o bom humor em pleno funcionamento, [...].

Encadeamentos evocados: [ter 79 anos, no entanto estar gloriosa]; [ter 79 anos, no entanto ainda ser bela]; [ter 79 anos, no entanto ter a inteligência intacta]; [ter 79 anos, no entanto ser amante dos livros e do cinema]; [ter 79 anos, no entanto ter bom humor em pleno funcionamento].

Aspecto associado: IDADE AVANÇADA PT JOVIAL. Conexão estabelecida: similaridade entre os enunciados.

Trecho 2: [...] mas com uma deficiência comum a outros que nasceram na Idade da Pedra Lascada: entende bulhufas de computadores. Não usa smartphone, nem tablet, nem iPad.

Encadeamento evocado: [estar gloriosa aos 79 anos, ainda ser uma bela mulher, com inteligência intacta, amante dos livros e do cinema e com bom humor, no entanto não entender de computadores, não usar smartphones, nem tablet, nem iPad].

$\begin{array}{lll}\text { Aspecto JOVIAL } & \text { associado: } \\ \text { DESCONHECIMENTO DE TECNOLOGIA. } & \end{array}$

Conexão estabelecida: contiguidade entre os enunciados.

Trecho 3: Está alheia ao universo virtual, que, segundo ela, não lhe faz a menor falta. Perguntou a mim: "Tenho esse direito?".

Ela mesma respondeu: "Descobri que não, não tenho".

Encadeamento evocado: [estar alheia ao universo virtual, no entanto não ter esse direito].

$\begin{array}{llcr}\text { Aspecto associado: } & \text { DESCONHECIMENTO } & \text { DE } \\ \text { TECNOLOGIA PT } & \text { NEG-DIREITO } & \text { [DE } \\ \text { DESCONHECER TECNOLOGIA]. } & \end{array}$

Conexão estabelecida: contiguidade entre os enunciados.

Trecho 4: Vive sozinha há uns 25 anos e os filhos moram em suas próprias casas: [...].

Encadeamento evocado: [ter 79 anos, no entanto viver sozinha há 25 anos].

Aspecto associado: IDOSA PT INDEPENDENTE.

Conexão estabelecida: contiguidade entre os enunciados dos trechos 1 e 4. 
Trecho 5: a família é unida, mas eles não são onipresentes.

Encadeamento evocado: [filhos não serem onipresentes, no entanto ter uma família unida].

Aspecto associado: NEG-ONIPRESENÇA PT UNIÃO FAMILIAR.

Conexão estabelecida: contiguidade entre os enunciados.

Trecho 6: Nem ela deseja que estejam na sua cola, é independente o suficiente para fazer suas compras, praticar exercícios, encontrar suas amigas, ir ao banco.

Ah, ir ao banco.

Encadeamento evocado: [ter 79 anos, no entanto ser independente para fazer suas compras, praticar exercícios, encontrar as amigas e ir ao banco].

Aspecto associado: IDOSA PT INDEPENDENTE.

Conexão estabelecida: similaridade entre os enunciados dos trechos 4 e 6.

Trecho 7: Ela é correntista de um grande banco que foi absorvido por outro grande banco, coisa que todo cliente é obrigado a aceitar sem direito a dar pitaco. Ok, nenhum problema. Só que é uma mulher que gosta de ter tudo na ponta do lápis, até porque este "tudo" não é tanto assim. Ela faz contas, como qualquer cidadã. Através do extrato do seu cartão de crédito, confere seus gastos mensais.

Encadeamento evocado: [ser independente, portanto fazer contas].

Aspecto associado: INDEPENDENTE DC RESPONSÁVEL [PELOS PRÓPRIOS GASTOS].

Conexão estabelecida: contiguidade entre os enunciados.

Trecho 8: Até que soube que seu banco, agora sob nova direção, não emitiria mais extratos de papel, apenas extratos online. Ela pensou: isso é bom, economia de celulose, mas eles certamente abrirão exceção para quem está fora das redes.

Encadeamento evocado: [banco não emitir mais extratos de papel, portanto emitir apenas extratos online].

Aspecto associado: NEG-EMISSÃO DE EXTRATO IMPRESSO DC EMISSÃO DE EXTRATO ONLINE.

Conexão estabelecida: contiguidade entre os enunciados.
Trecho 9: $E$ muito calmamente foi até sua agência solicitar a continuidade do recebimento do extrato pelo correio.

Foi tratada como se fosse um alienígena, um ser primitivo a ser estudado por arqueólogos. Saiu de lá sem a solução para essa questão que Ihe parecia tão simples, e é.

Encadeamento evocado: [ter direito à continuidade do recebimento do extrato pelo correio, no entanto ser tratada como um alienígena, um ser primitivo a ser estudado por arqueólogos].

Aspecto associado: DIREITO DE DESCONHECER TECNOLOGIA PT NEG-DIREITO [DE DESCONHECER TECNOLOGIA] SER RECONHECIDO.

Conexão estabelecida: contiguidade entre os enunciados.

Trecho 10: Pergunta ainda não respondida: idosos (e nem tão idosos) são obrigados a se informatizar? Humilhá-los é uma forma de punição pelo atrevimento de não terem um iToken?

Encadeamento evocado: [idosos terem o direito de desconhecer tecnologia, no entanto serem humilhados por não terem um iToken].

Aspecto associado: DIREITO DE DESCONHECER TECNOLOGIA PT NEG-DIREITO [DE DESCONHECER TECNOLOGIA] SER RECONHECIDO.

Conexão estabelecida: similaridade entre os enunciados dos trechos 9 e 10.

Trecho 11: Se você não viu o filme Eu, Daniel Blake, vencedor do Festival de Cinema de Cannes do ano passado, procure assistir por algum canal pago ou pelo DVD: trata da alienação forçada e injusta imposta àqueles que pegaram a revolução tecnológica no meio do caminho e não são mais considerados pessoas que valham o esforço de um atendimento analógico.

Encadeamento evocado: [pegar a revolução tecnológica no meio do caminho, no entanto não valer o esforço de um atendimento analógico].

Aspecto associado: IDADE AVANÇADA PT NEGDIREITO [DE DESCONHECER TECNOLOGIA] SER RECONHECIDO. 
Conexão estabelecida: contiguidade entre os enunciados.

Trecho 12: A bela septuagenária aqui citada não é um personagem de cinema. É apenas mais uma entre tantos senhores e senhoras que se sentem excluídos por seus digníssimos gerentes de conta, que parecem esquecer que existe vida além dos aplicativos. Até onde sei, 0 dinheiro de alguém de 35 anos vale o mesmo que o dinheiro de quem tem o dobro dessa idade. Ou não? Bancos, lojas, repartições: não matem seus antigos clientes antes do tempo.

Encadeamento evocado: [idosos terem o direito de desconhecer tecnologia, no entanto sentirem-se excluídos por seus gerentes de conta].

Aspecto associado: DIREITO DE DESCONHECER TECNOLOGIA PT NEG-DIREITO [DE DESCONHECER TECNOLOGIA] SER RECONHECIDO.

Conexão estabelecida: similaridade entre os enunciados dos trechos 9, 10 e 12.
Tendo aplicado a metodologia proposta por esta pesquisa, parte-se, nas linhas seguintes, para a seção em que serão discutidos os resultados encontrados a partir da análise do discurso "A baixa cotação dos off-lines".

\section{Discussão}

Com 0 intuito de melhor apresentar os resultados encontrados na análise, faz-se a utilização do Quadro 1, que explicita os aspectos argumentativos expressos em cada um dos trechos analisados e o tipo de conexão estabelecida entre os enunciados. Observe-se:

Quadro 1 - Aspectos argumentativos expressos em cada trecho do discurso analisado e o tipo de conexão estabelecida entre os enunciados

\begin{tabular}{|c|c|c|c|c|}
\hline Trecho & Segmento A & CON & Segmento B & Tipo de conexão \\
\hline 1 & IDADE AVANÇADA & PT & JOVIAL & $\begin{array}{l}\text { Similaridade entre enunciados } \\
\text { do mesmo trecho }\end{array}$ \\
\hline 2 & JOVIAL & PT & $\begin{array}{c}\text { DESCONHECIMENTO DE } \\
\text { TECNOLOGIA }\end{array}$ & $\begin{array}{l}\text { Contiguidade entre enunciados } \\
\text { do mesmo trecho }\end{array}$ \\
\hline 3 & $\begin{array}{c}\text { DESCONHECIMENTO DE } \\
\text { TECNOLOGIA }\end{array}$ & PT & $\begin{array}{l}\text { NEG-DIREITO [DE } \\
\text { DESCONHECER } \\
\text { TECNOLOGIA] }\end{array}$ & $\begin{array}{c}\text { Contiguidade entre enunciados } \\
\text { do mesmo trecho }\end{array}$ \\
\hline 4 & IDOSA & PT & INDEPENDENTE & $\begin{array}{c}\text { Contiguidade entre enunciados } \\
\text { dos trechos } 1 \text { e } 4\end{array}$ \\
\hline 5 & NEG-ONIPRESENÇA & PT & UNIÃO FAMILIAR & $\begin{array}{l}\text { Contiguidade entre enunciados } \\
\text { do mesmo trecho }\end{array}$ \\
\hline 6 & IDOSA & PT & INDEPENDENTE & $\begin{array}{l}\text { Similaridade entre enunciados } \\
\text { dos trechos } 4 \text { e } 6\end{array}$ \\
\hline 7 & INDEPENDENTE & DC & $\begin{array}{l}\text { RESPONSÁVEL [PELOS } \\
\text { PRÓPRIOS GASTOS] }\end{array}$ & $\begin{array}{c}\text { Contiguidade entre enunciados } \\
\text { do mesmo trecho }\end{array}$ \\
\hline 8 & $\begin{array}{l}\text { NEG-EMISSÃO DE EXTRATO } \\
\text { IMPRESSO }\end{array}$ & DC & $\begin{array}{l}\text { EMISSÃO DE EXTRATO } \\
\text { ONLINE }\end{array}$ & $\begin{array}{c}\text { Contiguidade entre enunciados } \\
\text { do mesmo trecho }\end{array}$ \\
\hline 9 & $\begin{array}{c}\text { DIREITO DE DESCONHECER } \\
\text { TECNOLOGIA }\end{array}$ & PT & $\begin{array}{l}\text { NEG-DIREITO [DE } \\
\text { DESCONHECER } \\
\text { TECNOLOGIA] SER } \\
\text { RECONHECIDO }\end{array}$ & $\begin{array}{l}\text { Contiguidade entre enunciados } \\
\text { do mesmo trecho }\end{array}$ \\
\hline 10 & $\begin{array}{c}\text { DIREITO DE DESCONHECER } \\
\text { TECNOLOGIA } \\
\end{array}$ & PT & $\begin{array}{l}\text { NEG-DIREITO SER } \\
\text { RECONHECIDO }\end{array}$ & $\begin{array}{c}\text { Similaridade entre enunciados } \\
\text { dos trechos } 9 \text { e } 10\end{array}$ \\
\hline 11 & IDADE AVANÇADA & PT & $\begin{array}{l}\text { NEG-DIREITO SER } \\
\text { RECONHECIDO }\end{array}$ & $\begin{array}{l}\text { Contiguidade entre enunciados } \\
\text { do mesmo trecho }\end{array}$ \\
\hline 12 & $\begin{array}{c}\text { DIREITO DE DESCONHECER } \\
\text { TECNOLOGIA }\end{array}$ & PT & $\begin{array}{l}\text { NEG-DIREITO SER } \\
\text { RECONHECIDO }\end{array}$ & $\begin{array}{l}\text { Similaridade entre enunciados } \\
\text { dos trechos } 9,10 \text { e } 12\end{array}$ \\
\hline $\begin{array}{c}\text { Sentido } \\
\text { global }\end{array}$ & TER IDADE AVANÇADA & DC & \begin{tabular}{c|} 
TER O DIREITO [DE \\
DESCONHECER \\
TECNOLOGIA] RECONHECIDO
\end{tabular} & - \\
\hline
\end{tabular}

Fonte: Adaptado de Malcorra (2018). 
Com base no Quadro 1, depreende-se que o sentido global do discurso é construído ao longo de doze aspectos argumentativos, cada um dos quais expresso em uma parte de texto, ou melhor, em cada trecho. No trecho 1, tem-se uma série de julgamentos argumentativos conectados pelo processo de similaridade. Esses julgamentos compartilham, pois, a Al de idosa, expressa pelo mesmo aspecto argumentativo (IDADE AVANÇADA PT JOVIAL). Nos trechos 2 e 3 , há o acréscimo de dois novos blocos semânticos no texto, a partir da retomada do segundo segmento dos seus aspectos argumentativos anteriores (observe-se: IDADE AVANÇADA PT JOVIAL > JOVIAL PT DESCONHECIMENTO DE TECNOLOGIA > DESCONHECIMENTO DE TECNOLOGIA PT NEG-DIREITO [DE DESCONHECER TECNOLOGIA]). A conexão entre os enunciados se faz, pois, por contiguidade, havendo um único julgamento argumentativo em cada um dos referidos trechos. No trecho 4, estabelece-se uma conexão por contiguidade com os enunciados do trecho 1 , visto a relação estabelecida entre a $\mathrm{Al}$ de idosa e sua AE (IDOSA PT INDEPENDENTE).

No trecho 5, tem-se um novo julgamento argumentativo, o qual inaugura um novo bloco semântico no texto. Tem-se, pois, uma conexão por contiguidade entre os enunciados. Já no trecho 6 , estabelece-se uma conexão por similaridade com os enunciados do trecho 4, visto que ambos compartilham 0 mesmo aspecto argumentativo (IDOSA PT INDEPENDENTE), sendo diferentes os encadeamentos evocados. Nos trechos 7, 8 e 9, estabelece-se uma conexão por contiguidade entre os enunciados, visto a constituição de um único julgamento argumentativo em cada uma das referidas partes de texto.

Já no trecho 10, tem-se uma conexão por similaridade com os enunciados do trecho 9, uma vez que ambos trechos compartilham o mesmo aspecto argumentativo (DIREITO DE DESCONHECER TECNOLOGIA PT NEG-DIREITO [DE DESCONHECER TECNOLOGIA] SER RECONHECIDO), sendo diferentes os encadeamentos evocados. No trecho 11, por sua vez, tem-se uma conexão por contiguidade entre os enunciados, e, por fim, no trecho 12, estabelece-se uma conexão por similaridade com os enunciados dos trechos 9 e 10, visto que expressam o mesmo aspecto argumentativo (DIREITO DE DESCONHECER TECNOLOGIA PT NEG-DIREITO SER RECONHECIDO), sendo diferentes os encadeamentos evocados em cada uma das partes de texto.

Com base na análise de cada um dos trechos, pode-se sintetizar o sentido do discurso no aspecto argumentativo único TER IDADE AVANÇADA DC TER O DIREITO [DE DESCONHECER TECNOLOGIA] RECONHECIDO. Note-se que os dois segmentos que constituem o referido aspecto são expressos mais de uma vez ao longo do discurso. Assim, é interessante destacar, ainda com base no Quadro 1, as retomadas de sentido empreendidas no discurso. Destaca-se não só a reiteração de um dos segmentos que compõem os aspectos argumentativos, o que ocorre nos trechos 2, 3, 7, 9 e 11, mas também a reiteração de aspectos argumentativos como um todo, como pode-se observar nos trechos 6, 10 e 12. No primeiro caso, tem-se a repetição de um único segmento e a constituição de um novo bloco semântico, o que faz o tema do texto progredir. Já no segundo caso, tem-se uma relação de similaridade entre enunciados de trechos diferentes, visto que, em cada parte de texto em que ocorre a reiteração de um aspecto argumentativo inteiro, tem-se a constituição de mais um julgamento ou motivo argumentativo. Nesse sentido, as retomadas demonstram ser uma importante ferramenta tanto para a manutenção, como para a progressão temática, possibilitando que o texto mantenha a coerência no desenvolvimento de seu tema.

Salienta-se o domínio de ocorrências de conexão por contiguidade (oito ocorrências), em comparação com as ocorrências de conexão por similaridade (quatro ocorrências). Nessa perspectiva, vale lembrar o que Graeff (2012) destaca a respeito do processo de contiguidade. Segundo a autora, ele "[...] permite entender como o texto mantém a 
coerência no desenvolvimento de seu tema. Trata-se, nesse caso, da coerência linguístico-discursiva do texto". (GRAEFF, 2012, p. 207). Nos oito trechos analisados em que ocorre o processo de contiguidade $(2,3,4,5,7,8,9$ e 11), pode-se dizer, há uma progressão semântico-argumentativa do texto, garantida pela manutenção do tema e pela instalação de novos blocos semânticos.

Ainda no que se refere ao total das ocorrências dos dois processos descritos, cumpre ressaltar que os dados revelam não só ocorrências de conexões entre enunciados de um mesmo trecho, mas também entre partes de texto diferentes. A título de exemplificação, é interessante recorrer aos trechos 1 e 6 , referentes ao processo de similaridade, bem como aos trechos 3 e 4, referentes ao processo de contiguidade. No trecho 1 , evocam-se uma série de encadeamentos argumentativos conectados pelo processo de similaridade. Esses encadeamentos, ligados a um mesmo aspecto argumentativo, fazem parte de uma cadeia linear, isto é, estão postos um após o outro, no mesmo enunciado. O mesmo não ocorre no trecho 6 , visto que a conexão por similaridade se dá com uma outra parte de texto, no caso com o trecho 4 . Nesses casos, há a repetição de um aspecto argumentativo no quadro dos aspectos expressos no discurso. No trecho 3, por sua vez, há uma relação de contiguidade entre os enunciados da mesma parte de texto. Note-se que a referida conexão diz respeito aos dois segmentos do encadeamento argumentativo, entre os quais não é possível empregar a expressão por exemplo, apenas um conector como portanto ou no entanto, visto a constituição de único motivo argumentativo. Já no trecho 4, a conexão por contiguidade se dá com outra parte de texto, mais especificadamente, com o trecho 1.

Com base nisso, verifica-se que das oito ocorrências de conexão por contiguidade encontradas no discurso, sete ocorrências dizem respeito a enunciados de um mesmo trecho e apenas uma diz respeito a enunciados de trechos diferentes. Já das quatro ocorrências de conexão por similaridade encontradas no discurso, uma ocorrência diz respeito a enunciados de um mesmo trecho, enquanto três ocorrências dizem respeito a enunciados de trechos diferentes. A Figura 1 demonstra, pois, o que precede:

Figura 1 - Ocorrências de conexões por similaridade e por contiguidade entre enunciados de um mesmo trecho e entre enunciados de trechos diferentes

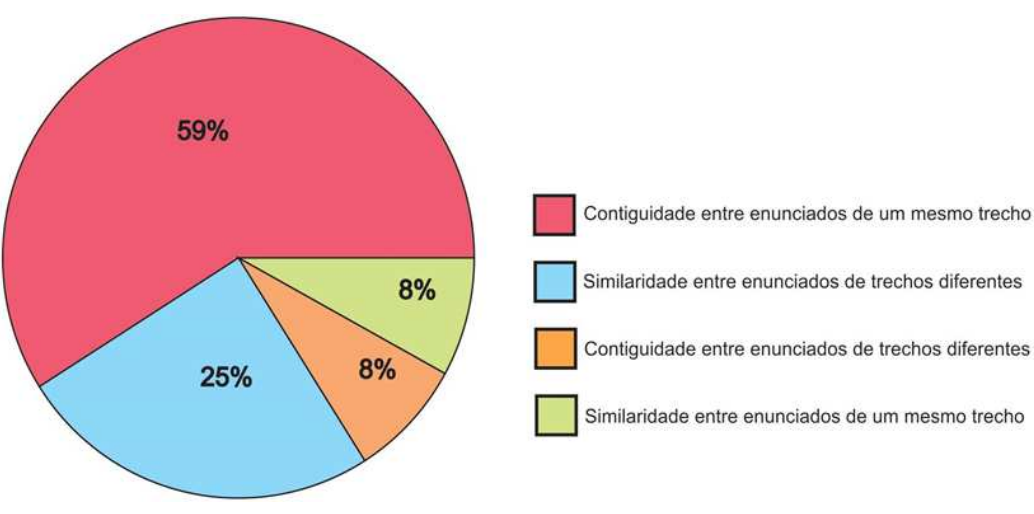

Fonte: Adaptado de Malcorra (2018).

Verifica-se, pois, que o processo mais frequente no discurso analisado é a conexão por contiguidade entre enunciados de um mesmo trecho (59\%). O segundo processo mais frequente é a conexão por similaridade entre enunciados de trechos diferentes (25\%). Essa constatação reitera a possiblidade de se falar em uma progressão semântico-argumentativa do texto, garantida pela manutenção do tema e pela instalação de novos blocos semânticos. As conexões por similaridade entre enunciados de um mesmo trecho e por contiguidade entre enunciados de trechos diferentes, por outro lado, não são recorrentes no discurso, o que abre a possibilidade de, em estudo futuros, verificar o funcionamento delas em outros textos.

Antes de finalizar, cumpre enfatizar a importância dos conceitos norteadores da Semântica Argumentativa para o estudo da organização dos sentidos do texto. Parte-se, na sequência, para as considerações finais deste estudo. 


\section{Considerações finais}

Este estudo teve como foco dois principais objetivos: (a) verificar como os motivos argumentativos se organizam no texto e (b) verificar de que modo as conexões estabelecidas entre os enunciados permitem explicitar o sentido global do discurso. Para o alcance do primeiro, buscou-se evocar os encadeamentos argumentativos, associados aos seus respectivos aspectos, que constituem o corpus selecionado, de acordo com a definição de motivo argumentativo dada por Carel (2012). Para o segundo, buscou-se identificar o tipo de conexão estabelecida em cada trecho, tendo em vista as definições dadas por Graeff (2012), sem perder de vista também os conceitos da TBS.

Interpretados os resultados, constatou-se que os dois processos descritos por Graeff (2012) ocorrem com frequência ao longo do discurso analisado. Não só isso, verificando o funcionamento desses processos, observou-se a ocorrência de conexões tanto no que diz respeito a enunciados de um mesmo trecho, como a enunciados de trechos diferentes.

Assim, a conexão por contiguidade entre enunciados de um mesmo trecho indica estabelecer uma relação em que não é possível colocar a expressão por exemplo entre os dois segmentos de um determinado encadeamento, apenas um conector como portanto ou no entanto. A conexão por similaridade entre enunciados de trechos diferentes, por sua vez, indica estabelecer uma relação entre encadeamentos argumentativos conectados a aspectos localizados em outras partes de texto. Nesses casos, há a reiteração de um mesmo aspecto argumentativo.

O mesmo não ocorre com a conexão por similaridade entre enunciados de um mesmo trecho, uma vez que, nessas ocorrências, os encadeamentos ligados a um mesmo aspecto argumentativo fazem parte de uma cadeia linear, isto é, estão postos um após o outro, no mesmo enunciado. Por fim, a conexão por contiguidade entre enunciados de trechos diferentes, que ocorre quando há uma relação entre a $\mathrm{Al}$ e a $\mathrm{AE}$ de uma entidade linguística, diz respeito a relações entre partes de texto mais distantes umas das outras.

Constata-se, com base nessas ocorrências, o domínio da conexão por contiguidade entre enunciados de um mesmo trecho, seguida da conexão por similaridade entre enunciados de trechos diferentes. Essa constatação reitera, pois, a possibilidade de se falar em uma progressão semântico-argumentativa do texto, garantida pela manutenção do tema e pela instalação de novos blocos semânticos.

Quanto às conexões por similaridade entre enunciados de um mesmo trecho e por contiguidade entre enunciados de trechos diferentes, verifica-se apenas uma ocorrência de cada. Essa constatação pode encontrar justificativa nos padrões composicionais da crônica, que, de acordo com estudiosos da área, é um gênero híbrido, de pouca estabilidade. (GLEDSON, 1990; LOPEZ, 1992). Nessa perspectiva, é importante ressaltar que Graeff (2012), em seu artigo sobre as conexões, analisa textos dissertativos, diferentemente do corpus escolhido para este estudo. Dessa forma, torna-se necessária a realização de novas pesquisas, a fim de verificar o funcionamento dos processos descritos em uma amostra mais robusta de crônicas, bem como em outros gêneros.

Destaca-se, por fim, a retomada de um dos segmentos que compõem os aspectos argumentativos e, também, a retomada de aspectos argumentativos como um todo. Essa constatação abre a possibilidade de propor soluções para os problemas levantados pela Linguística do Texto, no que se refere aos estudos de referenciação. Além disso, destacam-se os casos de encapsulamento anafórico encontrados nos discursos analisados, os quais, segundo Graeff (2007), não só podem remeter a um dos segmentos que constituem o encadeamento argumentativo, mas também a encadeamentos como um todo. Abre-se, assim, a possibilidade de novas investigações, a fim de testar tais constatações em outros textos.

Espera-se, com este estudo, ter apontado caminhos para uma melhor compreensão da 
organização dos sentidos do texto com base na Semântica Argumentativa. Espera-se, também, ter incitado reflexões a respeito de uma descrição do conteúdo argumentativo dos textos, bem como sobre o fazer do linguista nesse cenário. Em trabalhos futuros, resta, ainda, aprofundar os objetivos aqui propostos, com o intuito de verificar o funcionamento dos processos de similaridade e de contiguidade em outros textos, bem como a aplicação de conceitos da TBS, tais como motivo argumentativo, enriquecendo, assim, o campo teórico/prático da pesquisa.

\section{Referências}

CAREL, Marion. Introduction. In: CAREL, Marion (Org.). Argumentation et polyphonie: de Saint Augustin à Robbe-Grillet. Paris: L'Harmattan, 2012, p. 7-58.

CAREL, Marion; DUCROT, Oswald. La semántica argumentativa: una introducción a la teoría de los bloques semánticos. Buenos Aires: Colihue, 2005.

DUCROT, Oswald. La sémantique argumentative peut-elle se réclamer de Saussure? In: SAUSSURE, Louis de. Nouveaux regards sur Saussure: mélanges offerts à René Amacker. Genève: Droz, 2006, p. 153-170.

GLEDSON, John. Introdução. Tradução de Lourdes Dias. In: ASSIS, Machado. Bons dias! Edição, introdução e notas de John Gledson. São Paulo: Editora HUCITEC, 1990.

GRAEFF, Telisa Furlanetto. A conexão entre os enunciados no texto com base na semântica argumentativa. Desenredo, Passo Fundo, v. 8, n. 2, p. 197-208, jul./dez, 2012.

JAKOBSON, Roman. Essais de linguistique générale 1. Les fondations du langage. Paris: Minuit, 2003.
LOPEZ, Telê Porto Ancora. A crônica de Mário de Andrade: impressões que historiam. In: CANDIDO, Antonio et al. A crônica: o gênero, sua fixação e suas transformações no Brasil. Campinas: Editora da UNICAMP, 1992, p. 165-188.

MALCORRA, Bárbara Luzia Covatti. A organização semântico-argumentativa do discurso: um estudo sobre as conexões entre enunciados. 2018. Dissertação (Mestrado em Linguística) Programa de Pós-Graduação em Letras, Pontifícia Universidade Católica do Rio Grande do Sul, Porto Alegre, 2018.

MEDEIROS, Martha. A baixa cotação dos off-lines. Zero Hora, Porto Alegre. Disponível em: $<$ https://gauchazh.clicrbs.com.br/colunistas/martha -medeiros/noticia/2017/03/a-baixa-cotacao-dosoff-lines-9758735.html>. Acesso em: 13 nov. 2017.

\section{COMO CITAR ESSE ARTIGO}

MALCORRA, Bárbara Luzia Covatti. Conexão por similaridade e conexão por contiguidade: a organização dos motivos argumentativos do texto. Signo, Santa Cruz do Sul, v. 44, n. 80, p. 87-97, jul. 2019. ISSN 1982-2014. Disponível em: <https://online.unisc.br/seer/index.php/signo/article/view/13169>. Acesso em: doi: https://doi.org/10.17058/signo.v44i80.13169. 